\title{
Pedicle screw placement in spinal neurosurgery using a 3D-printed drill guide template: a systematic review and meta- analysis
}

\author{
Chengqiang Yu, Yufu Ou, Chengxin Xie, Yu Zhang, Jianxun Wei and Xiaoping Mu*
}

\begin{abstract}
Background: Many surgeons believe that the use of a 3D-printed drill guide template shortens operative time and reduces intraoperative blood loss compared with those of the free-hand technique. In this study, we investigated the effects of a drill guide template on the accuracy of pedicle screw placement (the screw placed completely in the pedicle), operative time, and intraoperative blood loss.

Materials/Methods: We systematically searched the major databases, such as Medline via PubMed, EMBASE, Ovid, Cochrane Library, and Google Scholar, regarding the accuracy of pedicle screw placement, operative time, and intraoperative blood loss. The $x^{2}$ test and $l^{2}$ statistic were used to examine heterogeneity. Odds ratios (ORs) with 95\% confidence intervals (Cls) were used to calculate the accuracy rate of pedicle screw placement, and weighted mean differences (WMDs) with 95\% Cls were utilized to express operative time and intraoperative blood loss.

Results: This meta-analysis included 13 studies (seven randomized controlled trials and six prospective cohort studies) involving 446 patients and 3375 screws. The risk of research bias was considered moderate. Operative time $(W M D=-20.75,95 \% \mathrm{Cl}-33.20 \sim-8.29, P=0.001)$ and intraoperative blood loss (WMD $=-106.16,95 \% \mathrm{Cl}-185.35$ $\sim-26.97, P=0.009$ ) in the thoracolumbar vertebrae, evaluated by a subgroup analysis, were significantly different between groups. The 3D-printed drill guide template has advantages over the free-hand technique and improves the accuracy of pedicle screw placement $(\mathrm{OR}=2.88 ; 95 \% \mathrm{Cl}, 2.39 \sim 3.47 ; P=0.000)$.
\end{abstract}

Conclusion: The 3D-printed drill guide template can improve the accuracy rate of pedicle screw placement, shorten operative time, and reduce intraoperative blood loss.

Keywords: Drill guide template, Pedicle screw, Free-hand technique, Pedicle screw fixation

\section{Introduction}

The malpositioning of pedicle screws (pedicle screw placement inaccuracy) is one of the most difficult problems encountered in pedicle screw fixation and often leads to a series of complications after surgery, such as nerve root injury, spinal cord injury, and surrounding soft tissue or bone destruction [1,2]. The incidence of pedicle screw misplacement can be as high as $15 \sim 30 \%$ in severe spinal deformity surgeries [3]. It is well known that screw misplacement has unpredictable clinical

\footnotetext{
* Correspondence: JXWei1972@163.com; muxbin1991@hotmail.com Department of Orthopaedics, The People's Hospital of Guangxi Zhuang Autonomous Region, Nanning, Guangxi 530021, China
}

consequences for the patient. Reoperation or removal of the screw not only increases the patient's financial burden and the pressure on the doctor but also leads to unnecessary waste of medical resources [4]. Therefore, it is very important to enhance the accuracy rate of pedicle screw placement using auxiliary equipment. To improve the accuracy rate of screw insertion, many new technologies have been developed, such as CT navigation and robotics. In addition, it has also been found that the complete insertion of screws in the pedicle is closely related to the surgeon's proficiency in surgery and postoperative X-ray assessment [5]. The current computerassisted imaging navigation system used for guiding

(C) The Author(s). 2020 Open Access This article is distributed under the terms of the Creative Commons Attribution 4.0 International License (http://creativecommons.org/licenses/by/4.0/), which permits unrestricted use, distribution, and 
pedicle screw placement has been used since the end of the twentieth century. In 1999, Kamimura et al. [6] used computer-assisted navigation systems to achieve satisfactory results in both laboratory and clinical settings. Therefore, to enhance clinical outcomes, we should improve the surgical proficiency of spine surgeons and develop more advanced equipment.

Recently, according to the reports of relevant clinical experiments, the drill guide template has been successfully applied in the placement of pedicle screws in spine surgeries [7-9]. Some studies have shown that patientspecific drilling guidance templates can reduce the incidence of pedicle screw misplacement and decrease the operative time and intraoperative blood loss; however, most of these studies involved animal experiments and cadaver specimen experiments [10-12]. Fan et al. [13] compared the screw perforation rates of the two methods, but cadaver experiments were included in their studies, and outcome indicators such as operative time and intraoperative blood loss were not systematically evaluated. In addition, Chen et al. [14] suggested that the drill guide template does not improve the accuracy rate of screw placement compared with that of the traditional method.

In view of the controversies and the inadequacies of current clinical studies, we conducted a meta-analysis of related studies to determine whether the drill guide template can increase the accuracy rate of screw placement as well as whether it decreases the operative time and intraoperative blood loss compared with those of the freehand technique.

\section{Methods}

\section{Search}

In accordance with the research purpose, two authors (C.Q.Y. and X.P.M.) searched relevant electronic databases, such as Medline via PubMed, EMBASE, Ovid, Cochrane Library, and Google Scholar. The time range of the articles included in the search was from the database establishment date to August 2019. The main keywords were as follows: drill guide template, patientspecific drill template, pedicle screw, free-hand technique, and pedicle screw fixation. The language of the articles was not limited. In addition, we manually searched the relevant literature to determine whether these documents met the inclusion criteria of this study. Finally, we carefully read the full text of the articles that met the inclusion criteria and extracted relevant data for a comprehensive evaluation.

\section{Inclusion criteria and exclusion criteria}

The inclusion criteria of the literature included the following aspects:
(1) Studies that included patients with a spinal disease requiring pedicle screw fixation, such as atlantoaxial instability, scoliosis, or severe spinal stenosis;

(2) Only clinical studies that included both a template group and a freehand group;

(3) Studies that included an observation group who underwent surgery with a screw navigation template containing a drill hole;

(4) Studies that included a control group who underwent surgery with a traditional hand-placed screw;

(5) Only clinical studies, including clinical randomized controlled trials and retrospective case-control studies.

When we encountered the following conditions, we excluded the corresponding article.

(1) Summaries, letters, case reports, and summaries of meetings;

(2) Studies with incomplete or unavailable data;

(3) Duplicate publications, studies with animal experiments, and cadaveric experimental studies;

(4) Gray literature and articles with poor quality evaluation or low credibility.

\section{Data extraction and quality assessment}

The data were independently extracted by two researchers (C.Q.Y. and Y.F.O) from eligible articles. The data included the following: name of the first author, year of publication, location of the study, year of the study, type of intervention, demographic characteristics (number, sex, and age), number of total screws, number of qualified screws, number of misplaced screws, operative time, and intraoperative blood loss. Since the evaluation criteria for the screw placement level were different among studies, we divided the inserted screws into qualified (screw completely within pedicle) and unqualified categories according to the postoperative CT scan results. The extraction of continuous data, such as operative time and intraoperative blood loss, mainly included the mean and standard deviation (mean, SD).

We used the risk of bias assessment tool provided by the Cochrane Handbook for Systematic Reviews of Interventions [15] to assess the quality of randomized clinical controlled trials. The quality assessment of the RCTs was carried out using the software Review Manager Version 5.1 (Cochrane Collaboration, Software Update, Oxford, UK). The nine-star Newcastle-Ottawa Scale (NOS) [16] was used to evaluate the quality of clinical observational studies. The Newcastle-Ottawa Scale is a validated tool for the quality assessment of nonrandomized studies, including cohort and case-control studies, and contains the following categories: selection of cohorts (four items), comparability of cohorts (one item), and assessments of outcomes (three items). A study can be awarded a maximum of one star for each item within the selection of 
cohort and assessment of outcome categories and two stars for the items in the comparability of cohort category. The scores of the items identifying study quality varied from zero to nine. Any disagreement was settled by a group discussion with a third investigator.

\section{Statistical analysis}

For the included studies that reported raw dichotomous data, the odds ratios (ORs) with 95\% confidence intervals (CIs) were calculated, and for the extracted continuous data, the weighted mean differences (WMDs) with 95\% confidence intervals (CIs) were calculated. The heterogeneity between the studies was calculated by the $\chi^{2}$ test and $I^{2}$ statistic. When $P>0.1$ and $I^{2}<50 \%$, there was no heterogeneity, and we used a fixed effects model; otherwise, we used a random effects model to pool the data. In addition, we used a subgroup analysis to assess the robustness of the meta-analysis results. When the eligible studies were adequate $(n \geq 10)$, funnel plots of Begg's test were examined for the existence of publication bias. All statistical analyses were performed using Stata (version 12.0). All $P$ values were two-sided, and $P<0.05$ was considered statistically significant.

\section{Results}

\section{Literature search results}

The search strategy initially produced 523 articles, and 184 articles remained after 339 duplicate documents were excluded. Another 163 irrelevant articles were then excluded after the study titles and abstracts were screened. Then, 4 animal studies and 4 cadaver specimen studies were excluded from the 21 studies that met the inclusion criteria. Finally, 13 eligible trials $[14,17-28]$ were included in this meta-analysis. The flow diagram for the literature selection is shown in Fig. 1.

\section{Characteristics and quality assessment of the included studies}

Table 1 shows the basic characteristics that were independently extracted by two authors (the first and second authors) from the 13 studies. All studies included at least one observational outcome, and the research was recently published. Five studies were published by foreigners, and the other eight studies were written by Chinese researchers. These studies involved a total of 466 patients. A total of 1700 pedicle screws were placed using the drill navigation

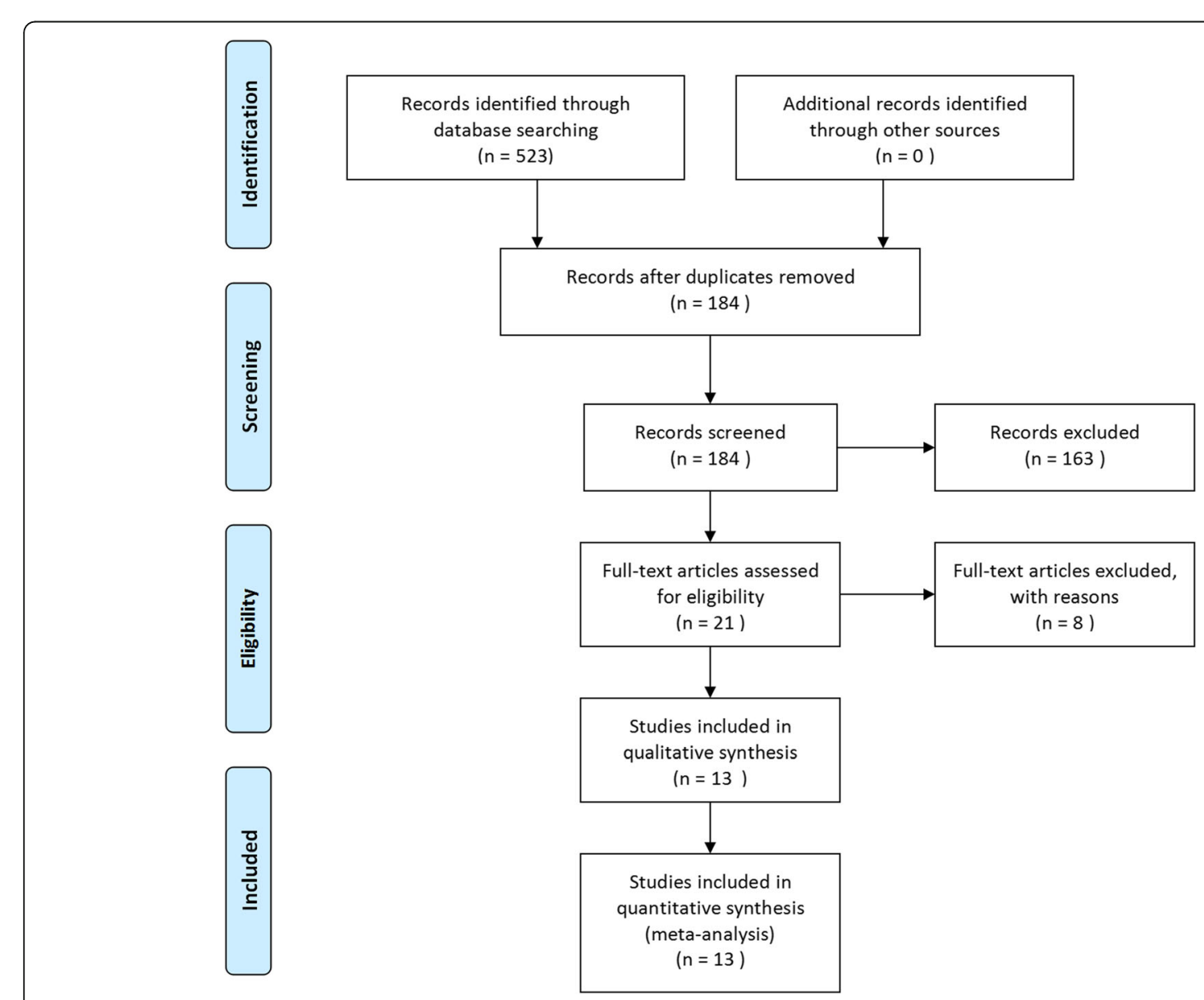

Fig. 1 Flow chart 
Table 1 The characteristics of the extracted research data

\begin{tabular}{|c|c|c|c|c|c|c|c|c|c|c|c|c|c|}
\hline Author & $\begin{array}{l}\text { Publication } \\
\text { year }\end{array}$ & $\begin{array}{l}\text { Study } \\
\text { location }\end{array}$ & $\begin{array}{l}\text { Study } \\
\text { year }\end{array}$ & Group & $N$ & $\begin{array}{l}\text { Age (year), } \\
\text { mean (SD) }\end{array}$ & $\begin{array}{l}\text { Male, } \\
\text { (male/ } \\
\text { female) }\end{array}$ & $\begin{array}{l}\text { Number } \\
\text { of total } \\
\text { screws }\end{array}$ & $\begin{array}{l}\text { Number } \\
\text { of } \\
\text { qualified } \\
\text { screws }\end{array}$ & $\begin{array}{l}\text { Number } \\
\text { of } \\
\text { misplace } \\
\text { screws }\end{array}$ & $\begin{array}{l}\text { Operative } \\
\text { time } \\
\text { (min), } \\
\text { mean } \\
\text { (SD) }\end{array}$ & $\begin{array}{l}\text { Blood } \\
\text { loss } \\
(\mathrm{ml}), \\
\text { mean } \\
(\mathrm{SD})\end{array}$ & $\begin{array}{l}\text { Other } \\
\text { outcomes }\end{array}$ \\
\hline $\begin{array}{l}\text { Cecchinato } \\
\text { R }\end{array}$ & 2019 & Italy & $\begin{array}{l}2015.1- \\
2016.10\end{array}$ & $\begin{array}{l}\text { A } \\
B\end{array}$ & $\begin{array}{l}14 \\
15\end{array}$ & $\begin{array}{l}34(15.3) \\
26(17.2)\end{array}$ & $\begin{array}{l}2 / 12 \\
1 / 14\end{array}$ & $\begin{array}{l}297 \\
243\end{array}$ & $\begin{array}{l}224 \\
160\end{array}$ & $\begin{array}{l}73 \\
83\end{array}$ & UC & UC & (4)(5) \\
\hline Chen $\mathrm{H}$ & 2015 & China & $\begin{array}{l}2014.8- \\
2015.3\end{array}$ & $\begin{array}{l}\text { A } \\
B\end{array}$ & $\begin{array}{l}20 \\
23\end{array}$ & $\begin{array}{l}52.3(8.75) \\
55.4(8.75)\end{array}$ & $\begin{array}{l}9 / 11 \\
12 / 11\end{array}$ & $\begin{array}{l}118 \\
122\end{array}$ & $\begin{array}{l}108 \\
99\end{array}$ & $\begin{array}{l}10 \\
23\end{array}$ & UC & UC & (4) \\
\hline Garg B & 2018 & India & UC & $\begin{array}{l}\text { A } \\
B\end{array}$ & $\begin{array}{l}10 \\
10\end{array}$ & $\begin{array}{l}15.5(3.8) \\
16.6(4.9)\end{array}$ & $\begin{array}{l}3 / 7 \\
4 / 6\end{array}$ & $\begin{array}{l}137 \\
126\end{array}$ & $\begin{array}{l}125 \\
104\end{array}$ & $\begin{array}{l}12 \\
22\end{array}$ & $\begin{array}{l}235.3 \\
(55.7) \\
298.5 \\
(59.3)\end{array}$ & $\begin{array}{l}630 \\
(227.6) \\
840 \\
(533.3)\end{array}$ & (4)(5) \\
\hline Guo F & 2017 & China & UC & $\begin{array}{l}\text { A } \\
B\end{array}$ & $13^{*}$ & UC & UC & $\begin{array}{l}37 \\
37\end{array}$ & $\begin{array}{l}32 \\
23\end{array}$ & $\begin{array}{l}5 \\
14\end{array}$ & UC & UC & (4)(5) \\
\hline Jiang $L$ & 2017 & China & $\begin{array}{l}2012.6- \\
2014.12\end{array}$ & $\begin{array}{l}\text { A } \\
B\end{array}$ & $\begin{array}{l}25 \\
29\end{array}$ & $\begin{array}{l}43.5(10) \\
46.9(7.25)\end{array}$ & $\begin{array}{l}16 / 9 \\
18 / 11\end{array}$ & $\begin{array}{l}100 \\
116\end{array}$ & $\begin{array}{l}96 \\
103\end{array}$ & $\begin{array}{l}4 \\
13\end{array}$ & $\begin{array}{l}171.84 \\
(22.46) \\
182.76 \\
(28.4)\end{array}$ & $\begin{array}{l}309.20 \\
(33.41) \\
322.07 \\
(26.51)\end{array}$ & (1)(3)(5)(8) \\
\hline Liu K & 2016 & China & $\begin{array}{l}2011.10- \\
2015.3\end{array}$ & $\begin{array}{l}\text { A } \\
B\end{array}$ & $10^{*}$ & UC & UC & $\begin{array}{l}48 \\
104\end{array}$ & $\begin{array}{l}45 \\
82\end{array}$ & $\begin{array}{l}3 \\
22\end{array}$ & UC & UC & (6) \\
\hline Merc M & 2013 & Slovenia & $\begin{array}{l}2011- \\
2012\end{array}$ & $\begin{array}{l}A \\
B\end{array}$ & $\begin{array}{l}9 \\
10\end{array}$ & $\begin{array}{l}59(5) \\
62(12)\end{array}$ & $\begin{array}{l}4 / 5 \\
5 / 5\end{array}$ & $\begin{array}{l}54 \\
54\end{array}$ & $\begin{array}{l}50 \\
45\end{array}$ & $\begin{array}{l}4 \\
9\end{array}$ & $\begin{array}{l}143(113) \\
176(90)\end{array}$ & UC & - \\
\hline Merc M (2) & 2013 & Slovenia & UC & $\begin{array}{l}\text { A } \\
B\end{array}$ & $\begin{array}{l}7 \\
8\end{array}$ & UC & UC & $\begin{array}{l}30 \\
36\end{array}$ & $\begin{array}{l}26 \\
21\end{array}$ & $\begin{array}{l}4 \\
15\end{array}$ & UC & UC & - \\
\hline Merc M & 2017 & Slovenia & $\begin{array}{l}2011- \\
2013\end{array}$ & $\begin{array}{l}\text { A } \\
\text { B }\end{array}$ & $\begin{array}{l}11 \\
13\end{array}$ & $\begin{array}{l}60.6(6.7) \\
62.8(11.7)\end{array}$ & $\begin{array}{l}5 / 6 \\
6 / 7\end{array}$ & $\begin{array}{l}72 \\
72\end{array}$ & $\begin{array}{l}66 \\
43\end{array}$ & $\begin{array}{l}6 \\
29\end{array}$ & UC & UC & (1)(2)(3) \\
\hline Pan Y & 2018 & China & $\begin{array}{l}2014.1- \\
2017.6\end{array}$ & $\begin{array}{l}\text { A } \\
\text { B }\end{array}$ & $\begin{array}{l}20 \\
17\end{array}$ & $\begin{array}{l}16.3(1.8) \\
16.5(1.4)\end{array}$ & $\begin{array}{l}7 / 13 \\
6 / 11\end{array}$ & $\begin{array}{l}396 \\
312\end{array}$ & $\begin{array}{l}354 \\
234\end{array}$ & $\begin{array}{l}42 \\
78\end{array}$ & $\begin{array}{l}283(22.7) \\
285(25.8)\end{array}$ & UC & (6) \\
\hline PuX & 2018 & China & $\begin{array}{l}2013.6- \\
2016.6\end{array}$ & $\begin{array}{l}\text { A } \\
B\end{array}$ & $\begin{array}{l}25 \\
24\end{array}$ & UC & $\begin{array}{l}11 / 14 \\
14 / 10\end{array}$ & $\begin{array}{l}100 \\
96\end{array}$ & $\begin{array}{l}98 \\
72\end{array}$ & $\begin{array}{l}2 \\
24\end{array}$ & $\begin{array}{l}106.1 \\
(10.9) \\
138.2 \\
(21.7)\end{array}$ & $\begin{array}{l}185.0 \\
(59.5) \\
311.0 \\
(87.4)\end{array}$ & (1) (3) (8) \\
\hline Wu C & 2015 & China & $\begin{array}{l}2011.2- \\
2013.11\end{array}$ & $\begin{array}{l}\text { A } \\
B\end{array}$ & $\begin{array}{l}18 \\
24\end{array}$ & $\begin{array}{l}37.2(25-57) \\
38.7(27-56)\end{array}$ & UC & $\begin{array}{l}144 \\
192\end{array}$ & $\begin{array}{l}131 \\
135\end{array}$ & $\begin{array}{l}13 \\
57\end{array}$ & $\begin{array}{l}133.3 \\
(15.9) \\
162.2 \\
(21.7)\end{array}$ & $\begin{array}{l}735.1 \\
(127.7) \\
843.2 \\
(147.8)\end{array}$ & (2)(4) \\
\hline Zhang Y & 2015 & China & $\begin{array}{l}2013.12- \\
2014.12\end{array}$ & $\begin{array}{l}\text { A } \\
B\end{array}$ & $\begin{array}{l}10 \\
10\end{array}$ & $\begin{array}{l}11.9(4.2) \\
12.6(3.8)\end{array}$ & $\begin{array}{l}3 / 7 \\
2 / 8\end{array}$ & $\begin{array}{l}167 \\
165\end{array}$ & $\begin{array}{l}138 \\
98\end{array}$ & $\begin{array}{l}29 \\
67\end{array}$ & $\begin{array}{l}163.5 \\
(53.7) \\
164.0 \\
(48.7)\end{array}$ & $\begin{array}{l}455 \\
(447) \\
415 \\
(389)\end{array}$ & (1)(7) \\
\hline
\end{tabular}

*: the total number of participants in both group $A$ and $B, A$ template group, $B$ free-hand group, $T N$ total number, $N$ number of patients, UC unclear, $S D$ standard deviation, (1) VAS, (2) ODI, (3) follow-up in months, (4) mean time per screw, (5) number of fluoroscopy, (6) postoperative Cobb angle, (7) changes of creatinine level, (8) JOA

template, and 1675 pedicle screws were placed using the free-hand technique. Seven studies reported operative time, and five studies reported intraoperative blood loss.

The bias of the eligible seven randomized controlled trials is summarized in Fig. 2a. Six of the seven randomized controlled trials $[14,17,18,22-24]$ had a low risk of performance bias due to the random sequence generation method, and only one study [27] had a high risk due to selection bias. Five studies [18, 22-24, 27] had a high risk of performance bias with due to the method of blinding the participants and personnel, and the other studies had an unclear risk [14, 17]. One study [24] had a high risk of detection bias, and another study [22] had a high risk of attrition bias. As illustrated in Fig. 2b, these selected studies were rated as having good quality. The quality of six nonrandomized controlled studies $[19-21,25,26,28]$ was evaluated according to the Newcastle-Ottawa Quality Assessment Scale. The results are shown in Table 2. These studies obtained scores ranging from six stars to eight stars, which indicate that the quality of the articles is good.

\section{Meta-analysis results}

Qualification rate of pedicle screw insertion

As shown in Fig. 3, all studies reported that the pedicle screws were inserted by a drill guide template or the free-hand technique. These studies were not 

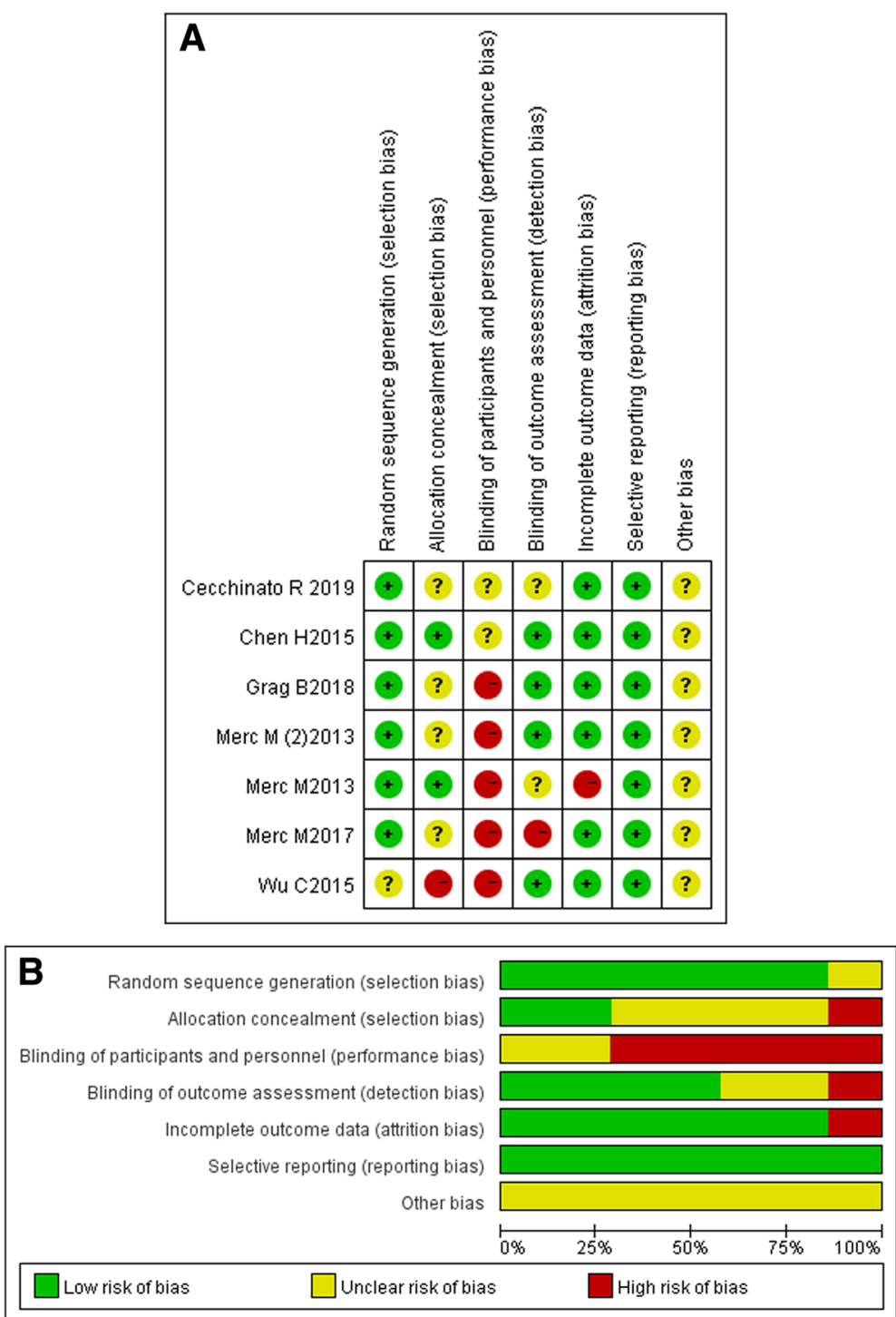

Fig. 2 Results of the quality assessment for each included study. (a) Summary of the risk bias; (b) Graph of the risk bias

heterogeneous $\left(I^{2}=45.7 \%, P=0.037\right)$, so the results were summarized using a fixed effects model. Considering the results of the control group, the drill guide template was more accurate than the free-hand technique in the insertion of the pedicle screws $(\mathrm{OR}=2.88 ; 95 \% \mathrm{CI}$, 2.39 3.47).

\section{Operative time}

As shown in Fig. 4, seven of the 13 studies [18, 20, 22, 25$28]$ reported operative time. Since the combined results indicated significant heterogeneity among studies $\left(I^{2}=66.1 \%\right.$, $P=0.007$ ), a random effects model was used to pool the results. The effect index $\mathrm{WMD}=-20.75$, the $95 \%$ CI $(-$

Table 2 NOS scores for six nonrandomized clinical controlled studies

\begin{tabular}{|c|c|c|c|c|}
\hline Included study & Selection & Comparability & Outcome & Final score \\
\hline Guo F 2017 & 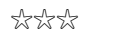 & ts & tots & 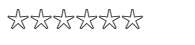 \\
\hline Jiang L 2017 & 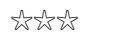 & $t_{2} t^{2}$ & tist & 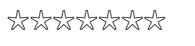 \\
\hline Liu K 2016 & 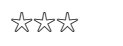 & ts & tistist & 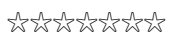 \\
\hline Pan Y 2018 & $t_{2} t^{2} t^{2} s^{2}$ & tots & is & 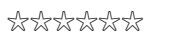 \\
\hline Pu X 2018 & $\sin \sin ^{2} t^{2}$ & tots & $\cos 2 \operatorname{sis}^{2}$ & 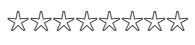 \\
\hline Zhang Y 2015 & tistist & tists & totsts & 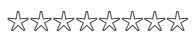 \\
\hline
\end{tabular}




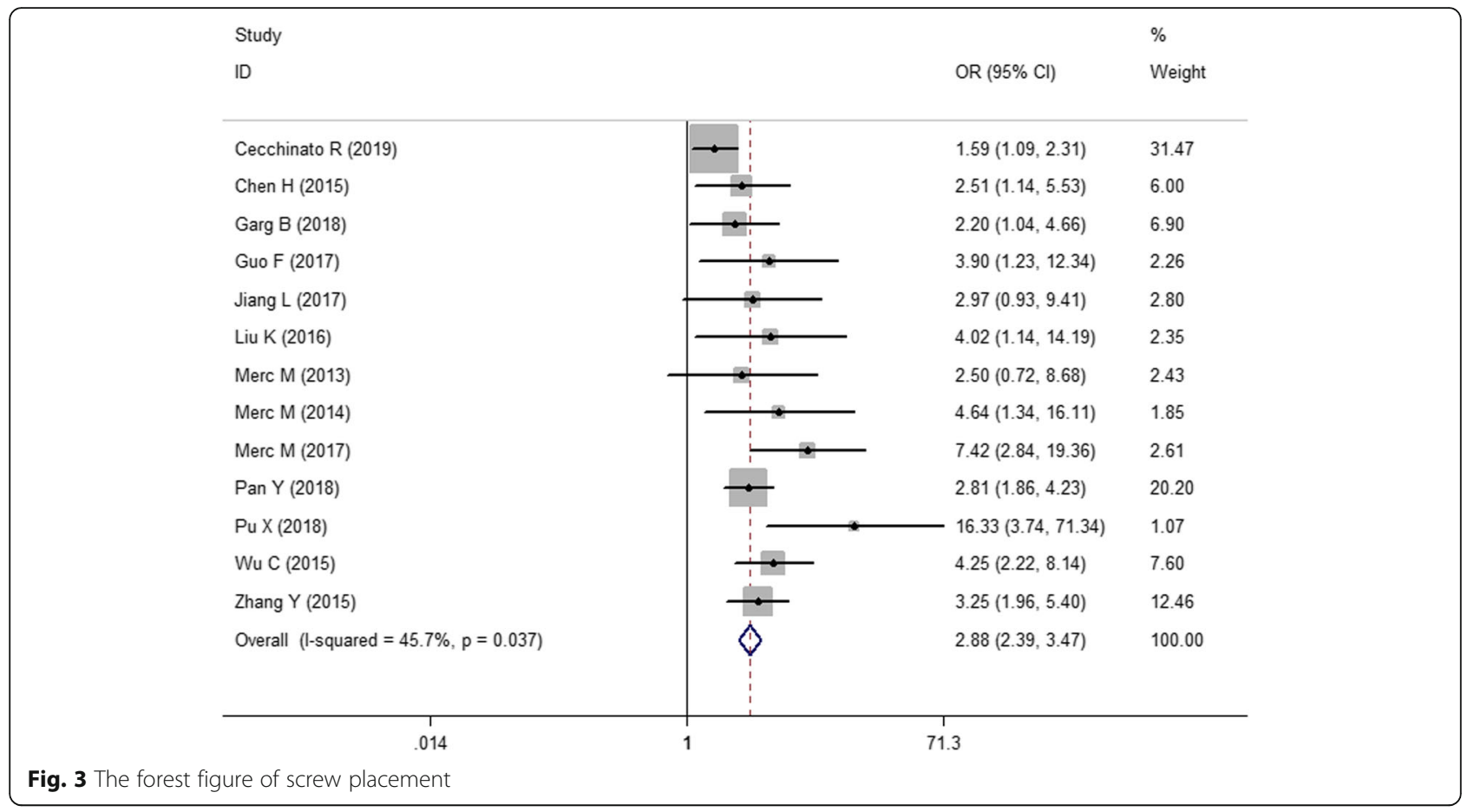

$33.20,-8.29)$, and the combined $P=0.001<0.05$ indicated that there was a statistically significant difference in the operative time between the two methods. Therefore, the drill guide template reduces the operative time in pedicle screw fixation compared with that of the free-hand technique.

\section{Intraoperative blood loss}

As shown in Fig. 5, five of the 13 studies [18, 20, 26-28] reported intraoperative blood loss. A random effects model was used to summarize the results because the heterogeneity was significant among five studies $\left(I^{2}=86.1 \%, P=0.000\right)$. Finally, we obtained the following results: $\mathrm{WMD}=-79.54,95 \%$ CI $(-161.89$, 2.81 ), and the combined $P=0.058>0.05$. There was no significant difference between the two groups. However, it is not clear whether the 3D-printed drill guide template resulted in less blood loss. Because the different surgical sites of patients led to different

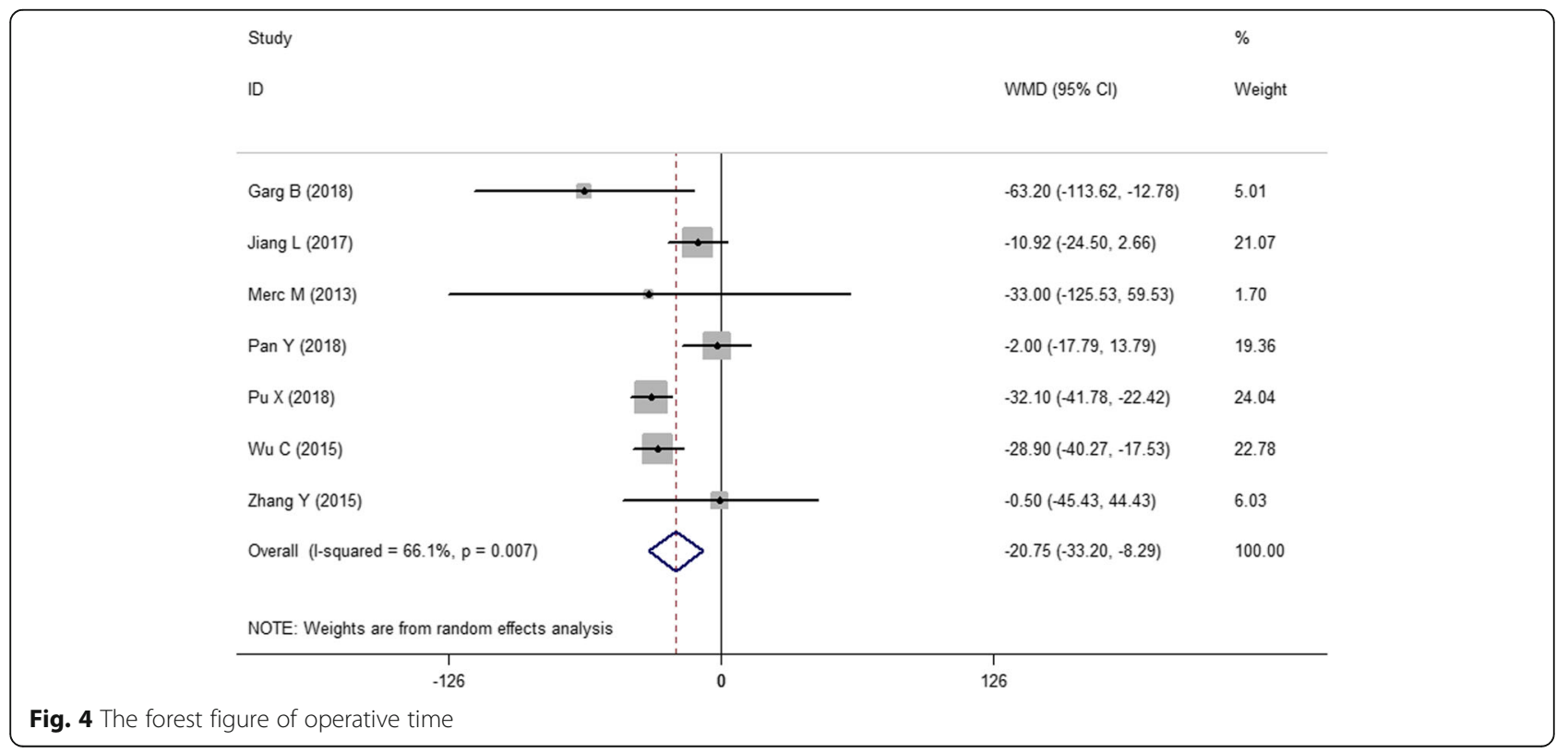




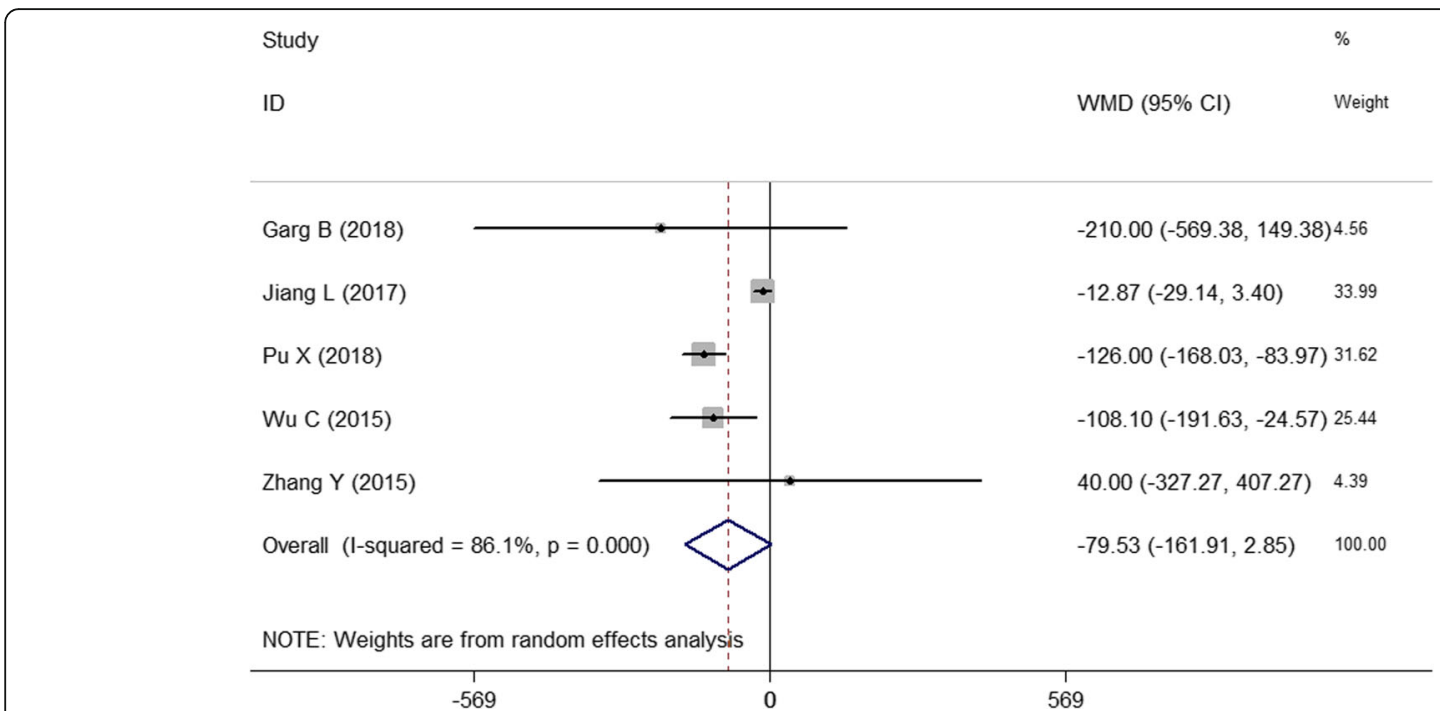

Fig. 5 The forest figure of blood loss

surgery outcomes, we should further analyze the sources of heterogeneity.

\section{Subgroup analysis}

Figure 3 shows the combined result of the number of correctly placed screws. Because $I^{2}=45.7 \%$, we did not perform a subgroup analysis. However, Figs. 4 and 5 show significant heterogeneity in operative time and intraoperative blood loss because the surgical sites of the spinal segments impact the surgical effects. Moreover, the selection of the surgical position depends on the affected spinal segments. Therefore, a subgroup analysis was performed according to the different spinal segments, e.g., the first group (thoracolumbar vertebrae group) and the second group (cervical vertebrae group).

Figure 6 shows the subgroup analysis of operative time. The two methods were statistically significant in the second group (cervical vertebrae group) (WMD = 22.07, 95\% CI, $-42.79 \sim-1.34$ ). Moreover, the results of the subgroup analysis indicate stability $[\mathrm{WMD}=-20.75$, 95\% CI $(-33.20,-8.29), P=0.037<0.05]$.

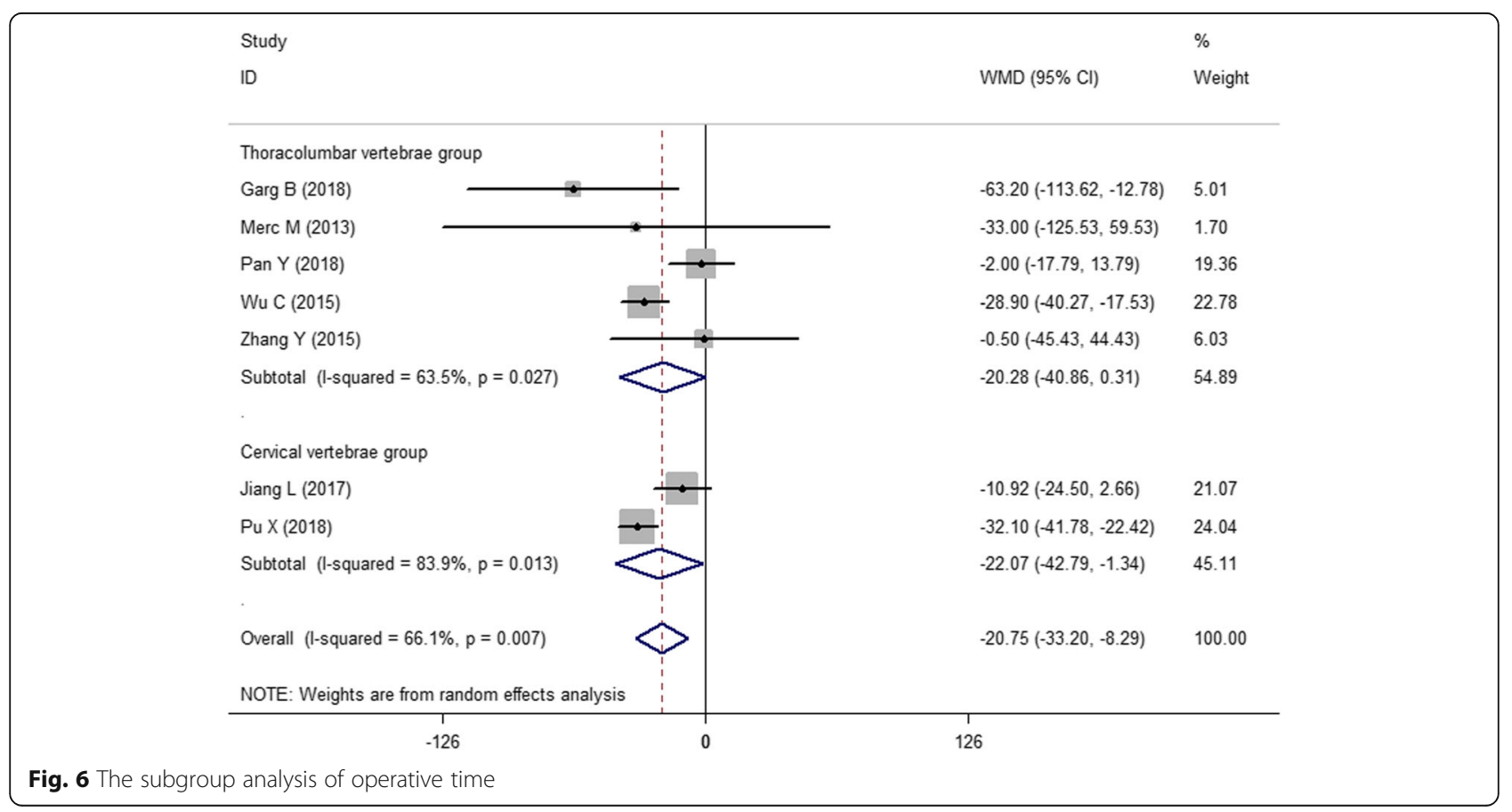


As shown in Fig. 7, a subgroup analysis of intraoperative blood loss showed a significant reduction in heterogeneity in the first group $\left(I^{2}=0.00 \%, P=0.628\right)$. The analytical result of the first group showed a statistically significant difference between the two methods [WMD = $-106.16,95 \%$ CI $(-185.35,-26.95), P=0.009<0.05]$. The results show that the different surgical sites or methods were sources of heterogeneity.

The drill guide template has an advantage over the free-hand technique in reducing the amount of intraoperative blood loss and the operative time.

\section{Publication bias}

As shown in Fig. 8, the Begg funnel plot shows substantial asymmetry. Begg's test indicated some evidence of publication bias (Begg's test, $P=0.044<0.05$; Egger's test, $P=$ $0.032<0.05)$. A reanalysis of the log-transformed data excluding the data of one study [17] showed a summary OR of 3.34 (95\% CI, 2.68-4.17, $I^{2}=0.00 \%, P$ for heterogeneity $=0.469)$ and no evidence of publication bias among the studies (Begg, $p=0.086$; Egger, $p=0.105$ ), indicating that methodological differences in data processing may partly explain the asymmetry of the funnel plot.

\section{Discussion}

In this meta-analysis, we evaluated the clinical efficacy (accuracy rate of the pedicle screws, operative time, and intraoperative blood loss) of two different interventions for patients with a severe spinal disease based on data from seven RCTs and six no-RCTs. This study indicates that drill guide templates significantly increase the accuracy rate of pedicle screw placement and decrease operative time and intraoperative blood loss compared with those of the free-hand technique.

The meta-analysis shows that the use of a patientspecific drill guide template that was made by $3 \mathrm{D}$ printing technology is superior to the traditional freehand technique. The use of a drill guide template can reduce the perforation rate of a misplaced screw during pedicle screw fixation. This result is similar to that reported by Fan et al. Currently, pedicle screws are usually placed by the free-hand technique. However, many researchers believe that pedicle screw placement using the free-hand technique is unreliable in cases of spinal deformity $[28,29]$. In addition to strengthening the surgeon's screw placement technique, we need to use some auxiliary devices. The drill guide template using a 3D printing technique may be the best choice at present [18]. This may be the best choice because 3D printing technology and related imaging equipment can provide the spinal surgeon a three-dimensional model or imaging data of the patient's diseased spine [30, 31]. There are different pedicle shapes, and 3D printing technology can produce many different drill guide templates that flexibly adjust the angle of the screw [7, 20, 32]. Though it improves the accuracy rate of the pedicle screw, the application of the technique is not more effective in reducing pain and disability after midterm follow-up in comparison with the free-hand technique [24].

There were significant differences between the two methods in terms of operative time in our study. The meta-analysis results showed that the drill guide template was more advantageous than the traditional free-

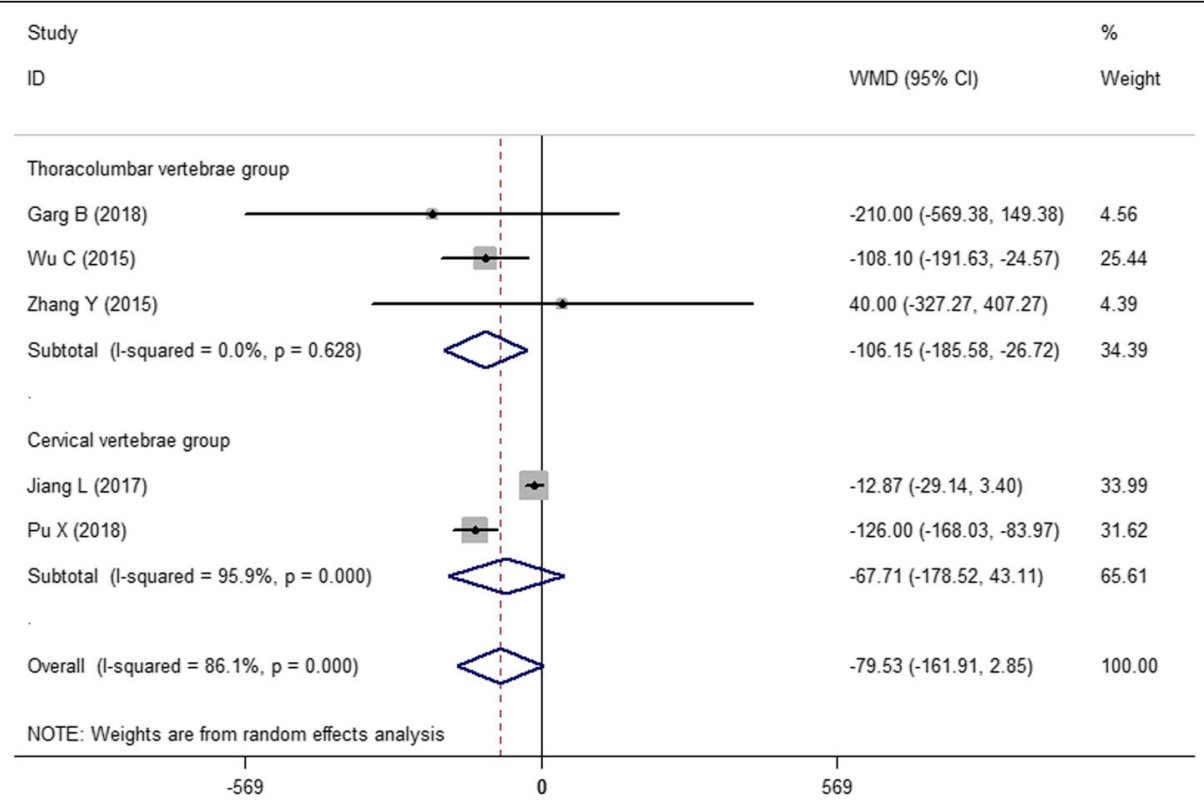

Fig. 7 The subgroup analysis of intraoperative blood loss 


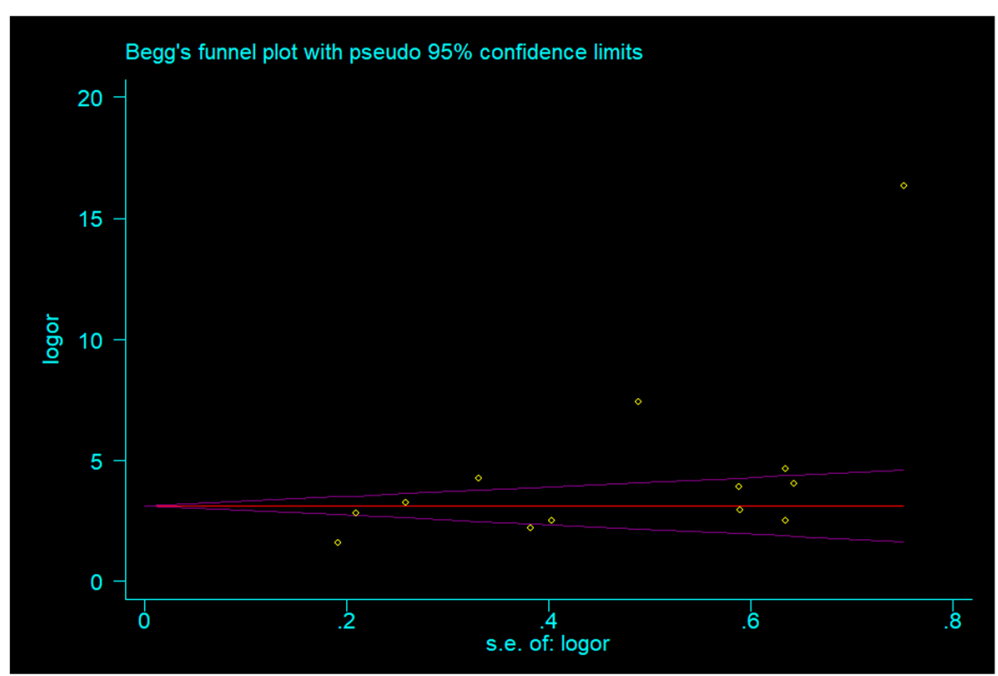

Fig. 8 Funnel plot of publication bias

hand technique was, and our subgroup analysis was stable and supported this result. Regarding with the intraoperative blood loss, there was no significant difference between the two groups in the total meta-analysis. However, considering that the different surgical sites and procedures can positively influence intraoperative blood loss, we thus performed a subgroup analysis. In the subgroup analysis for patients with thoracolumbar surgery, we can conclude that the drill guide template is superior to the free-hand technique in reducing intraoperative blood loss. The forest plot regarding intraoperative blood loss of cervical surgery in the subgroup analysis showed no statistical differences between the two treatments. Still, the confidence interval was skewed versus the group of free-hand technique. The confidence interval of the weighted mean difference (WMD) was wide and the possibility that the real WMD favors largely the group of drill guide template. We think that there are two factors contributing to the above results: the limited number of studies that we included and less intraoperative blood loss in the cervical surgery [33, 34]. This study illustrated the advantages of the drill guide template, which can accurately and effectively increase the accuracy rate of pedicle screw placement and decrease the risk of postoperative complications, such as shorten the operative time and reduce intraoperative blood loss. However, the drill guide template also has some disadvantages. First, to insert the pedicle screw in the ideal position during a fixation surgery, the spinal surgeon must clean or cut the soft tissue or bone tissue near the implantation site. This process will increase the chance of bleeding during surgery or relatively prolong the operative time [35]. Second, in minimally invasive spinal surgeries, there are problems such as a crowded operative space and unclear vision caused by surrounding tissue structures, which inevitably increases the surgeon's requirements for placing the screw [36]. Other issues associated with applying the drill guide template include template disinfection, template deformation, and the need to take time to learn the 3D printing software [35, 37].

The advantage of this meta-analysis is that the included studies do not have animal experiments or cadaver specimen experiments. Although previous studies have compared the accuracy rate of pedicle screw placement, their inability to simulate the true state of the clinical trials is their greatest drawback. Second, the secondary outcome of our meta-analysis determined whether the 3D printed drill guide template shortens operative time and reduces intraoperative blood loss. This outcome provides a reference for the selection of surgical methods in the future. For example, when a patient has a disease that cannot tolerate a long period of surgery, the spinal surgeon may have to consider other methods or formulate a contingency plan prior to the surgery.

However, there are also some limitations of our study. First, the number of articles and the sample size were small, which may affect the overall results. Second, we did not separate subjects by age, sex or disease type. Other factors affecting heterogeneity were not analyzed, such as we only scarcely mention the heterogeneity of the study population. Moreover, because the patients included these studies had different diseases, the results may be affected and need to be interpreted with caution. Finally, the number of eligible studies was obviously insufficient, as it included only seven randomized controlled trials; thus, the evidence provided by the meta-analysis may be inadequate. Moreover, there was publication bias in this meta-analysis, so we should interpret these results with caution. We hope that future 
work will include a larger number of studies and randomized clinical controlled trials with longer follow-up times and groups of patients with the same disease; a multicenter, prospective investigation should be considered. Meanwhile, there is a need for a scientific comparison of this technique with more methods, like computer navigation and robot arms.

\section{Conclusion}

In conclusion, the drill guide template significantly increases the accuracy rate of the pedicle screw and decreases operative time and interoperative blood loss compared with those of the free-hand technique. However, because our study has significant publication bias and other limitations, stricter studies with a larger sample size will help analyze these issues in the future.

\section{Abbreviations}

Cls: Confidence intervals; CT: Computed tomography; JOA: Japanese Orthopaedic Association Score; NOS: Newcastle-Ottawa Scale; ODI: The Oswestry Disability Index; ORs: Odds ratios; RCTs: Randomized controlled trials; SD: Standard deviation; TN: Total number; UC: Unclear; VAS: Visual Analogue Scale/Score; WMDs: Weighted mean differences

\section{Acknowledgements}

Not applicable.

\section{Authors' contributions}

CQ. Y conceived and designed the study. CQY, YFO, CXX, YZ, JXW, and XPM collected the data. CQY and XPM analyzed and interpreted the patient data. CQY wrote the paper. All authors read and approved the final manuscript. All authors have read the journal policies and have no issues relating to journal policies. All authors have seen the manuscript and approved to submit to your journal. The work described has not been submitted elsewhere for publication, in whole or in part.

\section{Funding}

This work was supported by the Guangxi Natural Science Foundation Program (2016GXNSFAA380058) and the Guangxi Medical and Health Research Fund Inc. (S2018026).

\section{Availability of data and materials}

The datasets generated and analyzed during the current study are available from the corresponding author on reasonable request.

\section{Ethics approval and consent to participate}

Not applicable.

\section{Consent for publication}

Not applicable.

\section{Competing interests}

The authors declare that they have no competing interests.

Received: 31 October 2019 Accepted: 5 December 2019

1.2. - 10

\section{References}

1. Delgado-Fernandez J, Garcia-Pallero MA, Blasco G, Pulido-Rivas P, Sola RG. Review of cortical bone trajectory: evidence of a new technique. Asian Spine J. 2017;11(5):817-31.

2. Siasios ID, Pollina J, Khan A, Dimopoulos VG. Percutaneous screw placement in the lumbar spine with a modified guidance technique based on 3D CT navigation system. J Spine Surg. 2017;3(4):657-65.
3. Sarlak AY, Tosun B, Atmaca H, Sarisoy HT, Buluc L. Evaluation of thoracic pedicle screw placement in adolescent idiopathic scoliosis. Eur Spine J. 2009;18(12):1892-7.

4. Korkmaz M, Sariyilmaz K, Ozkunt O, Gemalmaz HC, Akgul T, et al. Quantitative comparison of a laterally misplaced pedicle screw with a redirected screw. How much pull-out strength is lost? Acta Orthop Traumatol Turc. 2018;52(6):459-63.

5. Provaggi E, Leong JJH, Kalaskar DM. Applications of 3D printing in the management of severe spinal conditions. Proc Inst Mech Eng $\mathrm{H}$. 2017:231(6):471-86.

6. Kamimura M, Ebara S, Itoh H, Tateiwa Y, Kinoshita T, et al. Accurate pedicle screw insertion under the control of a computer-assisted image guiding system: laboratory test and clinical study. J Orthop Sci. 1999;4(3):197-206.

7. Sugawara T, Kaneyama S, Higashiyama N, Tamura S, Endo T, et al. Prospective multicenter study of a multistep screw insertion technique using patient-specific screw guide templates for the cervical and thoracic spine. Spine. 2018;43(23):1685-94.

8. Wang K, Zhang ZJ, Chen JX, Wu AM, Wang XY, et al. Design and application of individualized, 3-dimensional-printed navigation template for placing cortical bone trajectory screws in middle-upper thoracic spine: cadaver research study. World Neurosurg. 2019;125:e348-52.

9. Yu Z, Zhang G, Chen X, Chen X, Wu C, et al. Application of a novel 3D drill template for cervical pedicle screw tunnel design: a cadaveric study. Eur Spine J. 2017;26(9):2348-56.

10. Ge DW, Yang L, Chen X, Tang J, Chen HT, et al. A multi-level drill guide template improves the accuracy of pedicle screw placement in lumbar spine. Eur Rev Med Pharmacol Sci. 2018;22(12):3643-8.

11. Bundoc RC, Delgado GG, Grozman SA. A novel patient-specific drill guide template for pedicle screw insertion into the subaxial cervical spine utilizing stereolithographic modelling: an in vitro study. Asian Spine J. 2017;11(1):4-14.

12. Wang H, Liu Y, Zhao Y, Song G, Liu J, et al. Feasibility and accuracy of computer-assisted individual drill guide template for minimally invasive lumbar pedicle screw placement trajectory. Injury. 2018;49(3):644-8.

13. Fan Y, Du JP, Wu QN, Zhang JN, Hao DJ. Accuracy of a patient-specific template for pedicle screw placement compared with a conventional method: a meta-analysis. Arch Orthop Trauma Surg. 2017;137(12):1641-9.

14. Chen $H$, Wu D, Yang H, Guo K. Clinical use of $3 d$ printing guide plate in posterior lumbar pedicle screw fixation. Med Sci Monit. 2015;21:3948-54.

15. Furlan AD, Malmivaara A, Chou R, Maher CG, Deyo RA, et al. 2015 updated method guideline for systematic reviews in the cochrane back and neck group. Spine. 2015;40(21):1660-73.

16. Wells G, Shea B, O'Connell D, Peterson J, Welch V, et al. The NewcastleOttawa Scale (NOS) for assessing the quality of nonrandomised studies in meta-analyses. 2011.

17. Cecchinato R, Berjano P, Zerbi A, Damilano M, Redaelli A, et al. Pedicle screw insertion with patient-specific 3D-printed guides based on low-dose CT scan is more accurate than free-hand technique in spine deformity patients: a prospective, randomized clinical trial. Eur Spine J. 2019;28(7):1712-23.

18. Garg B, Gupta M, Singh M, Kalyanasundaram D. Outcome and safety analysis of 3D-printed patient-specific pedicle screw jigs for complex spinal deformities: a comparative study. Spine J. 2018;19(1):56-64

19. Guo F, Dai J, Zhang J, Ma Y, Zhu G, et al. Individualized 3D printing navigation template for pedicle screw fixation in upper cervical spine. PLoS One. 2017;12(2):e0171509.

20. Jiang L, Dong L, Tan M, Qi Y, Yang F, et al. A modified personalized imagebased drill guide template for atlantoaxial pedicle screw placement: a clinical study. Med Sci Monit. 2017;23:1325-33.

21. Liu K, Zhang Q, Li X, Zhao C, Quan X, et al. Preliminary application of a multi-level 3D printing drill guide template for pedicle screw placement in severe and rigid scoliosis. Eur Spine J. 2017;26(6):1684-9.

22. Merc M, Drstvensek I, Vogrin M, Brajlih T, Recnik G. A multi-level rapid prototyping drill guide template reduces the perforation risk of pedicle screw placement in the lumbar and sacral spine. Arch Orthop Trauma Surg. 2013;133(7):893-9.

23. Merc M, Drstvensek I, Vogrin M, Brajlih T, Recnik G. Use of rapid prototyping drill guide template for pedicle screw placement. Zdravniški Vestnik. 2013:82:395-401.

24. Merc M, Recnik G, Krajnc Z. Lumbar and sacral pedicle screw placement using a template does not improve the midterm pain and disability outcome in comparison with free-hand method. Eur J Orthop Surg Traumatol. 2017;27(5):583-9. 
25. Pan Y, Lu GH, Kuang L, Wang B. Accuracy of thoracic pedicle screw placement in adolescent patients with severe spinal deformities: a retrospective study comparing drill guide template with free-hand technique. Eur Spine J. 2018;27(2):319-26.

26. Pu X, Yin M, Ma J, Liu Y, Chen G, et al. Design and application of a novel patient-specific three-dimensional printed drill navigational guiding in atlantoaxial pedicle screw placement. World Neurosurg. 2018;11:e1-e10.

27. Wu C, Tan L, Lin X, Hu H. Clinical application of individualized reference model of sagittal curves and navigation templates of pedicle screw by threedimensional printing technique for thoracolumbar fracture with dislocation. Zhongguo Xiu Fu Chong Jian Wai Ke Za Zhi. 2015;29(11):1381-8.

28. Zhang YP, Shi YM, Wang HD, Hou SX. Case-control study on accuracy and safety of patient-specific drill-guide templates used in scoliosis cases. Zhongguo Gu Shang. 2015;28(10):945-50.

29. Baghdadi YM, Larson AN, McIntosh AL, Shaughnessy WJ, Dekutoski MB, et al. Complications of pedicle screws in children 10 years or younger: a case control study. Spine. 2013;38(7):E386-93.

30. Ling Q, He E, Ouyang H, Guo J, Yin Z, et al. Design of mulitlevel OLF approach ("V"-shaped decompressive laminoplasty) based on 3D printing technology. Eur Spine J. 2018;27(Suppl 3):323-9.

31. Liebmann F, Roner S, von Atzigen M, Scaramuzza D, Sutter R, et al. Pedicle screw navigation using surface digitization on the Microsoft HoloLens. Int J Comput Assist Radiol Surg. 2019;14(7):1157-65.

32. Thayaparan GK, Owbridge MG, Thompson RG, D'Urso PS. Designing patientspecific 3D printed devices for posterior atlantoaxial transarticular fixation surgery. J Clin Neurosci. 2018;56:192-8.

33. Liang J, Hu J, Chen C, Yin H, Dong F. Risk factors for predicting increased surgical drain output in patients after anterior cervical corpectomy and fusion. J Orthop Surg Res. 2017;12(1):196-201.

34. Yuan B, Zhou S, Chen X, Wang Z, Liu W, et al. Gallie technique versus atlantoaxial screw-rod constructs in the treatment of atlantoaxial sagittal instability: a retrospective study of 49 patients. J Orthop Surg Res. 2017;12(1):105-12.

35. Lu T, Liu C, Dong J, Lu M, Li H, et al. Cervical screw placement using rapid prototyping drill templates for navigation: a literature review. Int J Comput Assist Radiol Surg. 2016;11(12):2231-40.

36. Smith ZA, Fessler RG. Paradigm changes in spine surgery: evolution of minimally invasive techniques. Nat Rev Neurol. 2012;8(8):443-50.

37. Deng $T$, Jiang $M$, Lei $Q$, Cai L, Chen L. The accuracy and the safety of individualized 3D printing screws insertion templates for cervical screw insertion. Comput Assist Surg (Abingdon). 2016;21(1):143-9.

\section{Publisher's Note}

Springer Nature remains neutral with regard to jurisdictional claims in published maps and institutional affiliations.

Ready to submit your research? Choose BMC and benefit from:

- fast, convenient online submission

- thorough peer review by experienced researchers in your field

- rapid publication on acceptance

- support for research data, including large and complex data types

- gold Open Access which fosters wider collaboration and increased citations

- maximum visibility for your research: over $100 \mathrm{M}$ website views per year

At $\mathrm{BMC}$, research is always in progress.

Learn more biomedcentral.com/submissions 